\title{
Melanoidin İçeren Atık Suların Renginin Mikroorganizmalarla Giderilmesi
}

\section{Microbial Decolorization Of Melanoidin-Containing Wastewaters}

\author{
Rezan ALKAN* \\ Kocaeli Üniversitesi, Köseköy MYO, Fermentasyon Programı, Kocaeli
}

\begin{abstract}
Özet: Melanoidin pigmenti alkol damıtma ve maya üretim fabrikalarından çıkan atıklara koyu kahverengi renk veren biyopolimer kompleksidir. Organik maddelerde amino ve karbonil grupları arasında oluşan maillard reaksiyonları sonucunda meydana gelir. Bu renkli maddeler zor parçalanır ve verdikleri rengin giderimi zordur. Bu çalışmada melanoidinin özellikleri, çeşitli mikroorganizmalar ve kimyasal maddelerle suya verdiği rengin giderilmesine yönelik çalışmalar özetlenmiştir.
\end{abstract}

Anahtar kelimeler: Melanoidin, maillard reaksiyonları, renk giderimi.

Abstract: Melanoidin pigment is a complex biopolymer that gives the dark brown color to waste waters from alcohol distillers and from yeast production plants. The color is generated through maillard reactions between the amino and carbonyl groups of the organic materials. Since these colored substances are persistent chemicals, they are hardly decolorized. In this review, the properties of melanoidin and its decolorization by various microorganisms and chemical substances are summarized.

Key words: Melanoidin, maillard reactions, decolorization.

\section{Giriş}

Melanoidin pigmenti alkol damıtma veya ticâri maya üretimi sonucunda çıkan, melas içeren atık sularda bulunan koyu kahve renkli, yapısı karmaşık olan biyopolimerdir. Melanoidinler doğal olarak gıda ve içeceklerde de yaygın olarak bulunmaktadır (Painter, 1998). Yüksek oranda renk veren bu bileşiklerin parçalanması oldukça zordur (Miyata, 2000). Organik maddelerde bulunan amino ve karbonil grupları arasındaki maillard reaksiyonlarının sonucunda oluşur. İçerisinde melas gibi yüksek oranda renk içeren atık sular göl, nehir, deniz gibi ortamlara deşarj edildiğinde, alıcı ortamların bulanıklılığını arttırarak, güneş 1şığının suyun içerisine girişini azaltırlar. Bunun sonucunda sudaki yaşam fotosentez aktivitesi ve buna bağlı olarak çözünür oksijen konsantrasyonunun azalması nedeniyle zarar görür (Kumar vd, 1997). Toprağa atıldığı zaman da toprağın alkalinitesini azaltarak, o alanda vejetasyonun zarar görmesine neden olduğu gibi tohumların çimlenmesi üzerine de negatif etki yapmaktadır (Agarwal ve Pandey, 1994). Bu derleme, melasların renklenmesine neden olan melanoidinlerin kimyasal yapısı, mikrobiyolojik ve kimyasal olarak parçalanması ile bu bileşiklerin renginin giderilmesine yönelik bilgileri içermektedir.

\section{Melanoidin Polimerinin Yapısı}

Melanoidinler gıdaların işlenmesi ve saklanması sırasında enzimatik olmayan Maillard reaksiyonları adı verilen reaksiyonlar sonucunda oluşan, yüksek molekül ağırlığında amino karbonil bileşikleridir. Genellikle gıda ve diğer biyolojik örneklerden melanoidinleri ayırmak çok zordur ve bu yüzden melanoidinler hakkında kimyasal ve biyolojik çalışmalar model olarak seçilen melanoidinler üzerinde yapılmıştır (Chandra vd, 2008). Buna rağmen melanoidinlerin kimyasal yapısı açık bir şekilde anlaşılamamıştır. Fakat melanoidin modellerinin kimyasal yapılarının bir kısmı H NMR, CP-MAS NMR gibi farklı spektral çalışmalarla açıklanmıştır (Ikan vd, 1990, 1992, Larter ve Douglas,1980). Doğal ve sentetik melanoidinlerin CHON elementleri benzer bileşimdedir (Ikan vd., 1990;1992; Migo vd, 1997). N bileşiklerinin asitlikleri, elektroforetik davranışları yapılarında bulunan amino asitlerin fonksiyonel gruplarından kaynaklanmaktadır (Hedges, 1978). Benzing vd (1983), melanoidin polimerinde bulunan azotun sekonder amid şeklinde bulunduğunu, amid bağlarının asit hidrolizine dayanıklı olduğunu açıklamışlardır. Hayase (1984), bu polimerlerde mevcut olan ve glikozdan oluşan C-terminal yapılarla $\mathrm{CH}_{3}$-COR zincirinden oluştuğunu ileri sürerek, melanoidinlerin yapılarını aşă̆ıdaki şekilde özetlemiştir:

\footnotetext{
* İletişim: rezanalkan@kocaeli.edu.tr
} 


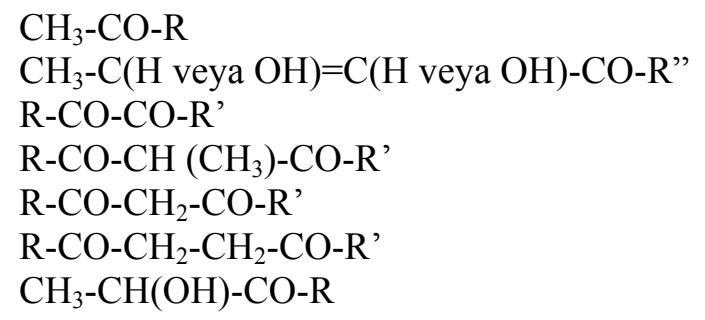

Cammerer vd., (2002), melanoidinlerin temel yapısının 3-deoksihekzosuloz ve amadori reaksiyon ürünlerinden oluştuğunu açıklamıştır. Melanoidinler negatif yüklüdür ve bunun için ağır metal iyonları, amino asitler, proteinler ve şekerlerle asidik ortamda birleşerek yüksek moleküller şeklinde çökerler (Migo, 1997). Hayase (1986), doymuş ve alifatik karbon atomlarının melanoidinlerin iskeletini oluşturduğunu açıklamış, ozon uygulamasının $\mathrm{C}=\mathrm{C}$ veya $\mathrm{C}=\mathrm{N}$ bağlarını parçalayabileceğini belirtmiştir. $\mathrm{Bu}$ doymamış bağların melanoidinlerin kromofor yapısında önemli olduğunu ileri sürmüştür. Yapılan bu çalışmalara rağmen, melanoidinlerin kromofor yapısı henüz kimliklendirilememiş, bu bileşiklerin kimyasal yapısı henüz açılanamamıştır. Tek bir tip melanoidin yoktur. Melanoidinlerin yapılarında olan farklılıklar, reaksiyona giren maddeler, $\mathrm{pH}$, sıcaklık ve reaksiyon süresi gibi reaksiyon koşullarına bağlı olarak değişim göstermektedir. Melanoidinlerin yapılarındaki kromoforların yapısının açıklanması için daha ileri teknikler kullanılarak, melanoidin polimerinin ana iskeletini çıkarmak için yoğun çalışmalar yapılmalıdır. Gıdalarda ve fizyolojik örneklerde Maillard reaksiyonu sonucunda oluşan ürünlerin kalitatif ve kantitatif olarak tayin edilmesi oldukça zordur. Proteinlerin asit hidrolizi esnasında oluşan bu ürünleri bilinen amino asit analizleri ile belirlemek zordur. Maillard reaksiyonu ile çok çeşitli ürünlerin oluşumu söz konusu olmaktadır. $\mathrm{Bu}$ ürünlerin saflaştırılması, teşhis edilmesi ve miktarlarının belirlenmesi gibi konular karşılaşılan en önemli sorunlardır. Doğrudan ve dolaylı olarak kullanılan birkaç metod vardır ( Ames vd, 1998; Jones vd, 1998; Shen, vd 2007. ve Silvan vd, 2006).

\section{Melanoidinlerin Parçalanması}

Amino- karbolil biyopolimeri olan melanoidinler doğada parçalanması zor olan kompleks polimerlerdir. Çevre kirliliğini azaltmak için kimyasal ve mikrobiyolojik olarak parçalama işlemleri gereklidir. Renk veren bu bileşiklerin parçalanabilmesi için kimyasal yapısının karakterize edilmesi gerekir.

\subsection{Kimyasal Olarak Parçalanması}

Birçok araştırıcılar doğal melanoidinler kadar, model olarak seçilen melanoidinlerin kimyasal olarak parçalanıp renginin giderilmesine yönelik çalışmalar yapmışlardır Cammerer vd, (2002). Amino asitlerle oligomer ve polimer yapida olan karbohidratlardan meydana gelen ve model olarak seçilen melanoidinlerin kimyasal olarak parçalanması üzerinde çalışmışlardır. Maillard reaksiyonlarında başlangıç maddesi olarak kullanılan karbonhidratların polimerizasyon derecesinin artması ile monosakkaritlerin açığa çıkmasının \%3 glisin ve \%95 dekstrin şeklinde olduğunu açıklamışlardır. Laktoz içeren melanoidinlerin esas hidroliz ürünü galaktozdur. Glukoz-glisinden hazırlanan model melanoidinlerin renginin kimyasal olarak gideriminde $\mathrm{H}_{2} \mathrm{O}_{2}$ kullanılmıştır (Hayase vd, 1984) . Melanoidinin bu maddeyle parçalanmasının $\mathrm{pH}$ değerine bağlı olduğu açıklanmıştır. İçerisinde \%6.72 oranında melanoidin içeren bir su örneğinde $\mathrm{H}_{2} \mathrm{O}_{2}$ ile muamele sonrasında melanoidinlerin molekül ağırlığının azaldığı belirtilmiştir. Nötral pH'da \%64, alkali pH'da (10) ise $\% 97$ oranında renk giderimi tespit edilmiştir. Kim vd, (1985) glukoz-glisinden hazırlanmış model melanoidinlerin ozon gazı uygulaması ile parçalanması ve renk giderimi üzerinde çalışmışlar, $10^{\circ} \mathrm{C}$ 'de 10 ve 90 dakika ozon uygulamışlar, 10 dakikada $\% 84,90$ dakikada ise $\% 97$ oranında renk giderimi sağlandığını gözlemişlerdir. Ozonlama yapıldıktan 40 dakika sonra melanoidinlerin molekül ağırlığının azaldığını açıklamışlardır. 


\subsection{Mikroorganizmalarla Parçalanması}

Renk giderimi çalışmalarında kimyasal uygulamalara alternatif olarak mikroorganizmalar kullanılmaktadır. Bazı anaerobik ve aerobik bakteri türlerinin melanoidin pigmentini parçalayıp kullanma özellikleri vardır (Ohmomo vd, 1988b). Lactobacillus hilgardii W-NS, Bacillus $s p$ (Nakojima-Kame vd, 1999; Kumar ve Chandra 2006); asetogenik bakteri BP103 ile (Sirianuntabipoon vd, 2004); Pseudomonas aeruginosa PA01, Stenotophomonas maltophila ile Proteus mirabilis (Mohana vd, 2007) gibi mikroorganizmalarla melanoidinin renk giderimi üzerinde çalışılmıştır. Bu bakterilerin geleneksel atık su arıtım sistemlerine adapte edilmesi, her bir türün optimum isteklerinin belirlenmesi ile ilgili çalışmalardaki zorluklar melanoidin pigmentinin renk giderimi çalışmalarını zorlaştırıcı etkenler olarak belirtilmiştir.

Melanoidin pigmenti içeren atık suların renginin giderilmesi için, Tayland'da koyu kahverengi lignin veya humus içeren toprak, fermente edilmiş meyve ve sebzeler, çürümüş meyve ve sebzeler gibi çeşitli kaynaklardan 2000 çeşit laktik asit bakterisi izole edilmiştir (Tondee vd, 2008). Seçilen bakteriler $475 \mathrm{~nm}$ dalga boyunda optik yoğunluğu 3.5 olan melanoidin içeren MRS agar ortamında renk giderimi için test edilmiştir. Melanoidin pigmentinin seçilen mikroorganizmalarla parçalanıp parçalanmadığı mikroorganizmaların besiyerinde geliştikleri kısımlarda oluşan şeffaf zonun çapı ölçülerek değerlendirilmiş ve bu zonun kalınlığına bağlı olarak 67 kültür seçilmiştir. Seçilen 67 adet tür sıv1 MRS ve melanoidin pigmenti içeren ortamlarda anoksik ve fakültatif koşullarda $30^{\circ} \mathrm{C}$ de 5 gün üretilmiş, hücreler ortamdan ayrıldıktan sonra geri kalan sıvının $475 \mathrm{~nm}$.de optik yoğunluğu ölçülerek, başlangıçtaki optik yoğunluk değerleri karşılaştırılmak suretiyle renk giderme verimleri saptanmıştır. Seçilen türlerin çoğunluğunun renk giderme değerleri \%15-25 arasında bulunmuştur. Sadece turşudan izole edilen gram $(+)$, katalaz $(-)$, mannoz, glukoz, fruktoz, galaktoz, arabinoz, maltoz, raffinoz ve laktozu kullanma özelliğinde olan, Lactobacillus plantarum No PV71-1861 kültürünün 7 günde renk giderim veriminin \%55 olduğu saptanmıştır. Renk giderme veriminin arttırılmasına yönelik yapılan çalışmalarda $\mathrm{C}$ kaynağı olarak glukoz, $\mathrm{N}$ kaynağı olarak maya özütü kullanıldığında üreme hızının arttığı ve buna bağlı olarak renk gideriminin de yüksek olduğu belirlenmiştir. Yapılan optimizasyon çalışmaları sonucunda; \%2 glukoz, \%0.4 maya özütü ve 2.53 $\mathrm{mg} / \mathrm{ml}$ melanoidin içeren ortamlarda $30^{\circ} \mathrm{C}$ de 7 günde $\% 68.12$ oranında renk giderimi elde edilmiştir (Tondee vd., 2008) . Lactobacillus hilgardii W-NS Melanoidin pigmentinin renginin gideriminde kullanılan ilk izole edilen laktik asit bakterisi kültürüdür (Ohmomo vd., 1988a). Anaerobik ve immobilize koşullarda renk giderme verimi sırası ile \%28 ve \%40 olarak bulunmuştur (Ohmomo vd.., 1988 a ve 1988 b). Yine Bacillus spp bakterisinin $55^{\circ} \mathrm{C}^{\prime}$ de anaerobik koşullarda 20 günde \%35.5 oranında renk giderdiği tespit edilmiştir (Nakajima-Kame vd., 1999). Gerek Lactobacillus hilgardii W-NS ve gerekse Bacillus spp bakteri türlerinin endüstriyel ölçekte, arıtım tesislerinde renk gideriminde kullanılmasının, sınırlandırılmış koşullardaki renk giderim verimlerinin düşük olması nedeniyle çok zor olduğu tespit edilmiştir (Metcalf ve Eddy, 2004). Lactobacillus plantarum No PV71-1861 nin renk giderim verimi bu türlerinkinden 2 misli fazla bulunmuştur. Melanoidin pigmenti içeren atık suların renginin gideriminin arttırılması için karbon kaynağı kullanılmasının, renk gideriminde rol oynayan şeker oksidaz ve peroksidazların aktivitesinin artış1 için gerekli olduğu çeşitli araştırıcılar tarafından açıklanmıştır (Chaturvedi vd., 2006; Kumar ve Chandra, 2006; Ohmomo vd., 1988 a; Sirianuntapiboon ve Chairattanawan, 1998). Melanoidin pigmentinin renginin giderilmesi için kullanılan Lactobacillus plantarum No PV71-1861 kültürünün renk giderim aktivitesi 24 saat içinde $\% 45$ dir. Bunun melanoidin pigmentinin adsorpsiyonu nedeni ile olabileceği açıklanmıştır. (Dahiya vd., 2001; Sirianuntapiboon vd., 1995). Bu türün melanoidinin küçük moleküllü kısımlarını parçaladığı, kültür sıvısında kalan büyük moleküllerin kalıntılarından anlaşılmıştır. Alınan sonuçların Lactobacillus hilgardii W-NS kültürü kullanılarak alınan sonuçlarla benzerlik gösterdiği açıklanmıştır (Ohmomo vd., 1988a ve 1988b).

Mavi-yeşil alglerle yapılan çalışmalarda, heterosist içermeyen, denizlerde yaşayan ve ipliksi yapısı olan Oscillatoria boryana BDU 92181 rrkının melanoidin içeren atık sularda renk giderimine katkısı olduğu, $\% 5$ oranında melanoidin içeren atık suların rengini 30 günde $\% 60$ oranında giderdiği 
saptanmıştır ( Kalavathi vd., 2001). Araştırmada, renk giderimi sonucunda ortamın pH'sının 9.6 olduğu tespit edilmiştir. Aynı araştırmada Phormidium valderianum BDU 30501 türünde ise renk giderim verimi \%55, ortam $\mathrm{pH}$ 'sı da 9.5 olarak tespit edilmiştir. Renk giderimine fotosentez sırasında oluşan moleküler oksijen, hidroksil anyonları ve hidrojen peroksitin neden olabileceği, alkali pH'da melanoidinin parçalanmasının hidroksil iyonları nedeni ile olduğunu açıklamıştır (Hayase vd., 1984). Hidroksil iyonlarının oluşumu ile melanoidin pigmentinin yapısında olan azot ve karbonun kullanılabilir şekle ayrışabildiği de belirtilmiştir. Hidroksil iyonlarının perhidroksil anyonları ile reaksiyona girerek oluşturduğu hidrojen peroksitin melanoidin pigmentinde renk giderimine yardımc1 olduğu da belirtilmiştir (Asada vd., 1987).

Basidiomycetes ve Ascomycetes fungi gruplarına ait olan türlerin doğal ve sentetik melanoidinlerin renginin gideriminde kullanıldı ̆̆ çeşitli araştırıcılar tarafından belirtilmiştir (Miranda vd., 1996; Raghukumar ve Rivonkar, 2001; Raghukumar vd., 2004; Thakkar vd., 2006) . Fakat daha ileri yapılı funguslar su ortamlarına kolaylıkla uyum gösterememektedirler. Ohmomo vd., (1985 b) Coriolus versicolour Ps-4a' nın melanoidin içeren atık sularda optimum koşullarda ve karanlıkta \%80 oranındaki renk giderimini saptamışlardır. Aspergillus oryzae Y-2-32 türünün misellerini otoklavlayıp kullandıklarında melanoidinlerin küçük molekül ağırlıklı moleküllerinin miseller tarafından adsorbe edildiğini açıklamışlardır. Miranda (1996), optimum şartlarda ve uygun besiyerinde Aspergillus niger kullanılarak yapılan bir çalışmada, melanoidin içeren atık sularda \%83 oranında renk giderimi olduğunu ve bu oranın \%17'sinin miseller tarafından adsorplandığını açıklamıştır. Raghukumar ve Rivonkar (2001), deniz fungusu olan Flavodon flavus türünün renk giderim kapasitesini araştırmışlardır. Büyük molekül ağırlığı olan fraksiyonların parçalandığını, küçük molekül ağırlı̆̆ındaki fraksiyonların ise metabolik reaksiyonlarda yavaş bir şekilde kullanıldığını

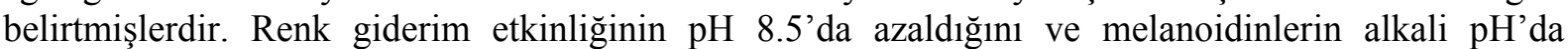
çözünür şekle dönüştüğünü, asit pH'da çökme gösterdiğini açıklamışlardır. Ohmomo vd.. (1985 b), mikroorganizmalarla melanoidinlerin parçalanmasının 2 mekanizmadan ibaret olduğunu açıklamıştır. Birincisi küçük, ikincisi ise büyük molekül ağırlığında olan fraksiyonların bağlanması şeklinde olmaktadır. Besin sınırlaması olan ortamlarda uzun süreli üretim esnasında fungus hücrelerinin aktivitesini yitirdiklerini, bundan dolayı sürekli kültürleme metotlarının pratik olmadığını belirtmişlerdir.

\section{Sonuç}

Hammadde olarak melas kullanan endüstriler için renk yönünden ciddi problem olan melanoidinin giderilmesine yönelik araştırmalar hâlâ yoğun bir şekilde devam etmektedir. Mikroorganizmalarla renk giderimine yönelik çalışmalar laboratuar düzeyinden endüstriyel boyuta taşınamamıştır. Çünkü her mikroorganizmanın optimum $\mathrm{pH}$, sıcaklık ve besin ihtiyacı farklı olabilmektedir. Yâni bu türlerin atık sulara adaptasyonu oldukça zor olabilmektedir. Endüstriyel boyutta melanoidin içeren atık suların mikroorganizmalar kullanılarak renk giderme amacıyla uzun süre bekletilmesi başka çevresel problemlerin (koku ve sinek oluşumu gibi) ortaya çıkmasına neden olabilir. Mavi-yeşil alglerle yapılan çalışmalarda, atık suyun renginin uzun sürede giderildiği açıklanmıştır. Aynı zamanda alglerin fotosentez için ışı ihtiyaçlarının olması nedeni ile atık suların seyreltilmesi gerektiği belirtilmektedir. Alg uygulaması ile renk gideriminin diğer dezavantajlı yönünün, renk giderimi sonrasında atık suların $\mathrm{pH}$ sının alkali yönde olmasıdır. Bilindiği gibi; $\mathrm{pH}$ 's1 yüksek olan atık sular alıcı ortama deşarj edilememektedir. $\mathrm{Bu}$ bir dezavantaj oluşturabilir. Mikroorganizmalarla yapılan renk giderimi çalışmalarında, atık sudan mikroorganizmaların uzaklaştırılması için en etkin ayırma yöntemlerinin uygulanması gerekmektedir. Mikroorganizmaların etkili bir şekilde uzaklaştırılamaması alıcı ortamın COD ve BOD değerlerinin artmasına sebep olur. Belki immobilizasyon yönteminin endüstriyel pilot arıtma tesislerinde etkili bir şekilde denenmesi tavsiye edilebilir. Kimyasal olarak renk giderimi çalışmalarında renk giderim sonucu ortaya çıkan katı atı̆̆ın uzaklaştırılması, pH gibi parametrelerin de önemli olduğu belirtilmiştir. Çalışmalarda en etkili yöntem ozonlama yöntemi olabilir; çünkü, bu yöntemde katı atık oluşmamaktadır. 


\section{Kaynaklar}

Agarwal, C.S.ve Pandey, G.S. 1994. Soil pollution by spent wash discharge: depletion of manganese (11) and impairment of its oxidation. Journal of Environmental Biology, 15: 49-53.

Ames, J.M., Defaye, A.B., Bailey, R.G. ve Bates, I. 1998. Analysis of the non-volatile Maillard reaction products in an extrusion-cooked model food system. Food Chem, 61: 521-524.

Asada, K., Takahashi, M. 1987. Production and scavenging of acive oxygen in photosynthesis. In: Kyle, DJ, Osmund CB, Arntzen CJ, editors, Photoinhibition. Amsterdam. Elsevier Science Publications, 27-228.

Benzing,P.L., Ripmeester, J.A. ve Preston, C.M. 1983. Elucidation of the nitrogen forms in melanoidins and humic acids by N15 cross polarization- magic angle spinning nuclear magnetic resonance spectroscopy. J.Agric. Food. Chem. 31: 913-915.

Cammerer , B., Jalyschkov, V. ve Kroh, L. W. 2002. Carbohydrate structures as part of the melanoidin skeleton. Int. Congr. Ser, 1245: 269-273.

Chandra,R., Bharagava, R.N ve Rai, V. 2008. Melanoidins as major colourant in sugarcane molasses based distillery effluent and its degradation. Bioresource Technology. 99: 4648-4660.

Chaturvedi, S., Chandra, R. ve Rai, V. 2006. İsolation and characterization of Phragmittes australis(L.) rhizosphere bacteria from contaminated site for bioremediation of colored distillery effluent. Ecological Engineering, 27: 202-207.

Dahiya, J., Singh, D. ve Nigam, P. 2001. Decolorization of synthetic and spentwash melanoidins using the white-rot fungus Phanerochaete chrysosporium JAG-40. Bioresource Technology,78:95-98.

Hayase, F., Kim, S.B. ve Kato, H. 1984. Decolorization and degradation products of the melanoidin by hydrogen peroxide. Agric. Biol. Chem, 48: 2711-2717.

Hayase, F., Kim, S.B. ve Kato, H. 1986. Analysis of the chemical structures of melanoidins by 13 CNMR, 13 C and 15 N CP-MAS NMR spectrometry. Agric. Biol. Chem, 50: 1951-1957.

Hedges, J.I. 1978. The formation and clay mineral reactions of melanoidins. Geochim. Cosmochim.Acta 42: 69-76.

Ikan, R., Dorsey, T. ve Kaplan, I.R. 1990. Characterization of natural and synthetic humic substances (melanoidins) by stable carbon and nitrogen isotope measurements and elemental compositions. Anal. Chim. Acta, 232: 11-18.

Ikan, R., Ioselis, P., Rubinsztain, Y., Aizenshtat, Z., Miloslavsky, I., Yariv, S., Pugmire, R., Anderson, L.L., Woolfenden, W.R., Kaplan, I.R., Dorsey, T., Peters, K.E., Boon, J.J., Leeuw, J.W.D., Ishiwatari, R., Morinaga, S., Yamamoto, S., Macihara, T., Vonmoos, M.M., ve Rub, A. 1992. Chemical, isotopic, spectroscopic and geological aspects of natural and synthetic humic substances. Sci. Total Environ, 117/118: 1-12.

Jones, A. D., Tier, C.M. ve Wilkins, J.P.G . 1998. Analysis of the Maillard reaction products of Betalactolglobulin and lactose in skimmed milk powder by capillary electrophoresis and electrospray mass spectrometry. J. Chromatogr.A, 822:147-154.

Kalavathi,D.F., Uma,L.ve Subramanian.G. 2001. Degradation and metabolization of pigmentmelanoidin in distillery effluent by the marine cyanobacterium Oscillatoria boryana BDU 92181. Enzyme and Microbial Technology , 29: 246-251.

Kim, S.B., Hayase, F. ve Kato, H. 1985. Decolorization and degradation products of melanoidins on ozonolysis. Agric. Biol. Chem. 49: 785-792.

Kumar, V., Wati,L., Nigam, P., Banat, I.M., Macmullan, G., Singh, D. ve Marchant, R. 1997. Microbial decolorization and bioremediation of anaerobically digested molasses spent wash effluent by aerobic bacterial culture. Microbios, 89: 81-89.

Kumar,P., Chandra,R. 2006; Decolorization and detoxification of synthetic molasses melanoidins by individual and mixed cultures of Bacillus spp. Bioresource Technology, 97 (16):2096-2102.

Larter, S.R., Douglas, A.G. 1980. Melanoidins-kerogen precursors and geocheical lipid sink: Astudy using pyrolysis gas chromatography (PGC). Geochim. Cosmochim.Acta, 44: 2087-2095. 
Metcalf., Eddy Inc. 2004. Wastewater Engineering Treatment Disposal and Reuse, 4th ed.

( International Edition), McGraw-Hill, New York, NY10020, USA, 545-1026.

Migo, V.P., Del Rosario, E.J.ve Matsumura, M. 1997. Flocculation of melanoidins induced by inorganic ions. J.Ferment.Bioeng, 83(3): 550-555.

Miranda, P.M., Benito, G.G., Cristobal, N.S.ve Nieto, C.H. 1996. Colour elimination from molasses wastewater by Aspergillus niger. Biores. Technol, 57: 229-235.

Miyata,N., Mori, T., Iwahori, K. ve Fujita, M. 2000. Microbial decolorization of melanoidin containing wastewaters: Combined use of activated sludge and the fungus Coriolus hirsutus. J.Biosci. Bioeng, 89: 145-150.

Mohana, S., Desai, C. ve Madamwar, D. 2007. Biodegradation and decolorization of anaerobically treated distillery spent wash by a novel bacterial consortium. Biores.Technol, 98: 333-339.

Nakajima-Kame,T., Shimomura, M., Nomra, N., Chanpornpong, T. ve Nakahava, T. 1999. Decolorization of molasses wastewater by Bacillus sp. Under thermphilic and anaerobic conditions. Journal of Bioscience and Bioengineering, 87:119-121.

Ohmomo, S., Itoh, N., Wantanabe, Y., Kaneko, Y., Tozawa, Y. ve Udea, K. 1985 b. Continuous decolorization of molasses wastewater with mycelia of Coriolus versicolor Ps4a. Agric. Biol. Chem, 49: 2047-2053.

Ohmomo ,S., Daengsubha, W., Yoshikawa, H., Yui, M., Nozaki, K., Nakajima, T. ve Nakamura, I. 1988a. Screening of anaerobic bacteria with the ability to decolorize molasses melanoidin. Agricultural and Biological Chemistry, 52: 2437-2441.

Ohmomo, S., Yoshikawa, H., Nozaki, K., Nakajima, A., Daengsubhar, W. ve Nakamura, I. 1988 b. Continuous decolorization of molasses wastewater using immobilized Lactobacillus hilgardii cell. Agricultural and Biological Chemistry, 52: 2437-2441.

Painter, T.J. 1998. Carbohydrate polymers in food preservation: an integrated view of the Maillard reaction with special reference to discoveries of preserved foods in Sphagnum-dominated peat bogs. Carbohyd.Polym, 36: 335-347.

Raghukumar, C., Rivonkar, G. 2001. Decolorization of molasses spent wash by white-rot fungus Flavodon flavus, isolated from a marine habitat. Appl. Microbiol. Biotechnol, 55: 510-514.

Raghukumar, C., Mohandass, C., Kamat, S., Shailaja, M.S. 2004. Simultaneous detoxification and decolorization of molasses spent wash by the immobilized white-rot fungus Flavodon flavus, isolated from a marine habitat. Enzyme Microb. Technol. 35: 197-202.

Shen, S.C., Tseng, K. C. ve Wu, J.S.B. 2007. An analysis of Maillard reaction products in ethanolic glucose-glycine solution. Food Chem, 102: 281-287.

Silvan, J.M., Lagemaat, J.V.D., Olano, A. ve Castillo, M.D.D. 2006. Analysis and biological properties of amino acid derivates formed by Maillard reaction in foods. J.Pharma. Biomed. Anal, 41: 1543-1551.

Sirianuntapiboon, S., Chairattanawan, K. 1998. Some properties of Coriolus sp.No.20 for removal of colour substances from molasses wastewater. Thammasat International Journal of Science and Technology, 3: 74-79.

Sirianuntapiboon,S., Shianonth, P., Somchai, P., Atthasumpunna, P. ve Hayashida, S. 1995. An absorption mechanism fort he decolorization of melanoidin by Rhizoctonia sp.D-90. Bioscience Biotechnology and Biochemistry, 59: 1185-1189.

Sirianuntabipoon, S., Phothilangka, P. ve Ohmomo, S. 2004. Decolorization of molasses wastewater by a strain No.BP103 of acetogenic bacteria. Bioresource Technology, 92: 31-39.

Thakkar, A.P., Dhamankar, V.S. ve Kapadnis, B.P. 2006. Biocatalytic decolorization of molasses by Phanerochaete chrysosporium. Biores. Technol, 97: 1377-1381.

Tondee, T., Sirianuntabipoon, S . 2008. Decolorization of molasses wastewater by Lactobacillus plantarum No.PV71-1861. Bioresource Technology, 99: 6258-6265. 